(C) 2019 International Journal of Nursing and Health Services

This is an Open Access article distributed under the terms of the Creative Commons Attribution 4.0 International License.

ORIGINAL ARTICLE

\title{
THE ROLE OF ENDORPHIN HORMONES AS PREDICTORS OF ANXIETY AMONG WOMEN WITH PREGNANCY
}

\author{
Putriatri Krimasusini Senudin ${ }^{*}$, Saidah Syamsuddin ${ }^{2}$, Andi Armyn \\ Nurdin²
}

1 Master of Midwifery Student, Hasanuddin University; Indonesia Chatolic University of Saint Paul Ruteng

2 Faculty of Medicine, Hasanuddin University

* Correspondence: atri124@gmail.com

\begin{abstract}
Pregnancy anxiety is a common problem with a prevalence of $14-54 \%$ and is the highest in the third trimester. This study aims to determine the relationship of endorphin hormone levels to pregnancy anxiety. This study was an observational study using a cross-sectional approach to 57 pregnant women. The anxiety level measured by using the Hamilton Anxiety Rating Scale (HARS) and the ELISA kit with plasma specimens were employed to examine the endorphin hormone levels. The results showed that endorphin hormone levels acted as predictors of pregnancy anxiety $(p=0,000)$.
\end{abstract}

Keywords: Anxiety, Pregnancy, Endorphin

International Journal of Nursing and Health Services (IJNHS), September 2019, Volume 2, Issue 3; Page 16-21

Received: 5 April 2019; Revised: 22 April 2019; Accepted: 05 May 2019

DOI: http://doi.org/10.35654/ijnhs.v2i3.107

\section{Introduction}

Pregnancy anxiety is a common problem with a prevalence of $14-54 \%$ and is the highest in the third trimester (1). Pregnancy anxiety was associated with increasing CRH, ACTH, and cortisol (2). The increasing CRH level at 25 weeks of the gestational period linked with labor induction, glucose transport to the placenta and fetal cells, and maternal psychology (3). Plasma CRH levels in pregnant women increase by 1,000 - 10,000 times that of non-pregnant women (4). CRH levels that remain high in pregnancy will inhibit the synthesis of endorphins that enter the peripheral circulatory system and contribute to mood disorders faced by pregnant and postpartum women (5-6). Anxiety during pregnancy adversely affects the health of the mother and fetus. Mothers who experience anxiety are three times more likely to experience postpartum blues and postpartum depression (7), the increase of high blood pressure risk, heart disease, and miscarriage (8). Experiencing pregnancy anxiety can increase the risk of health problems in the fetus until the age of children. There can be a decrease in fetal heart rate to the fetus, low response to an external stimulus, and a less active fetus (9). During the perinatal period, it can increase 
the risk of low birth weight (LBW), low Apgar scores, growth barriers, cognitive and social development disorders (10-11). During the neonatal period, it causes the baby to prolonged cry (12), easily angry and upset (13) and weak interactions between mother and child (14). Children born to mothers who experience anxiety during the pregnancy period can increase the risk of asthma, coronary heart disease, and a reduction in heart rate variability (15).

Endorphin is known to play a crucial role in depersonalization disorder. During pregnancy, endorphins play a position through the placental trophoblast tissue into the maternal blood circulation system, which starts in the third month of pregnancy, resulting in independent endorphin. Lack of endorphins during pregnancy causes pregnancy anxiety and therefore has the risk of psychopathology (16).

Consequently, it can be predictors that play a role in increasing or decreasing stress in which one of them is by knowing the levels of the hormone endorphin.

\section{Objectives}

This study aimed to determine the relationship between endorphin hormone levels with pregnancy anxiety.

\section{Method}

This study was an observational study with a cross-sectional approach. The samples in the study were 57 pregnant women who met the inclusion criteria. The inclusion criteria, including aged ranging from 20 to 35 years old, gestational period 25 to 36 weeks and experiencing pregnancy anxiety in the category of mild, moderate, severe, and very severe. The level of anxiety was measured by using the Hamilton Anxiety Rating Scale (HARS) instrument, which consisted of 14 components. The range of values 0-56 was categorized into five categories, such as not anxious, mildly anxious, moderate anxious, very anxious, and very anxious. To assess endorphin hormone levels, blood plasma samples were examined using Human Endorphins ELISA Kit. Data analysis using the one-sample ttest. Ethical feasibility in this study conducted by explaining the purposes and objectives of the research. The participation of respondents was voluntary and without coercion. The pregnant women who were willing to be the respondents were asked to sign an informed consent. Information about respondents only used for research purposes was guaranteed confidentiality.

\section{Results}

\subsection{Characteristics of respondents}

Respondents who participated in this study were 57 pregnant women. Table 1 reveals that the features of respondents based on the age of most pregnant women aged $31-35$ years $(35,1 \%)$, while others are $26-30$ years old $(33.3 \%)$ and at least $20-25$ years old (31.6\%). Based on education, most of the senior high $(47.4 \%)$, while others have a university (35.1\%), junior high (12.3\%) and at least elementary (5.3\%). Based on work, most pregnant women unemployed (80.7\%) while others employed (19.3\%). 
Table 1: Characteristics of respondents $(n=57)$

\begin{tabular}{lll}
\hline Variables & \multicolumn{2}{l}{ Pregnant women } \\
\cline { 2 - 3 } & $\mathrm{n}$ & $\%$ \\
\hline Age & 18 & 31,6 \\
20-25 years & 19 & 33,3 \\
26-30 years & 20 & 35,1 \\
31-35 years & & \\
\hline Education & 3 & 5,3 \\
$\quad$ Elementary & 7 & 12,3 \\
$\quad$ Junior High & 27 & 47,4 \\
Senior High & 20 & 35,1 \\
$\quad$ University & & \\
Work & 11 & 19,3 \\
Employed & 46 & 80,7 \\
$\quad$ Unemployed & & \\
\hline Parity & 19 & 33,3 \\
Primigravida & 38 & 66,7 \\
Multigravida & & \\
\hline Gestational age & 23 & 40,4 \\
25-28 weeks & 5 & 8,8 \\
28 weeks ${ }^{+1}$ day - 30 weeks & 8 & 14,0 \\
30 weeks +1 day - 32 weeks & 13 & 22,8 \\
32 weeks +1 day - 34 weeks & 8 & 14,0 \\
34 weeks ${ }^{+1}$ day - 36 weeks & &
\end{tabular}

\subsection{Anxiety levels of pregnant women}

Table 2 reveals that generally pregnant women experience moderate anxiety (56.1\%), following severe fear (22.8\%) and mild anxiety $(21.1 \%)$.

\begin{tabular}{lll} 
Table 2. Anxiety Levels of Pregnant Women $(\mathrm{n}=57)$ \\
\hline Variables & \multicolumn{2}{c}{ Pregnant women } \\
\cline { 2 - 3 } & $\mathrm{n}$ & $\%$ \\
\hline Mild anxiety & 12 & 21,1 \\
Moderate anxiety & 32 & 56,1 \\
Severe anxiety & 13 & 22,8 \\
\hline
\end{tabular}

\subsection{Relationship between endorphin hormone levels and anxiety of pregnant women}

In table 3 shows that the average stress of pregnant women (94.03) and the average level of endorphin hormone (25.0). The results of the analysis with the Mann Whitney $U$ test showed a value of $p=0,000(p<0,005)$ indicating that there was a relationship between pregnancy anxiety and endorphin hormone levels. Based on Figure 1, it can be seen that low levels of endorphin hormones are associated with an increase in 
pregnancy anxiety. The levels of endorphin and anxiety hormones are equally increased at the gestational period of 25-28 weeks, which continues to grow as the gestational period increases.

Table 3. relationship between endorphin hormone levels and anxiety of pregnant women

\begin{tabular}{llll} 
& \multicolumn{2}{c}{$(\mathrm{n}=57)$} & $\mathrm{p}$-value \\
\cline { 2 - 3 } Variable & Mean & \\
& 94,03 & 61,56 & 0,000 \\
\hline Endorphine Hormone Levels & 25,0 & 4,24 & \\
Anxiety Level & & &
\end{tabular}

Figure 1. Line Trends in Endorphin Hormones with Pregnancy Anxiety

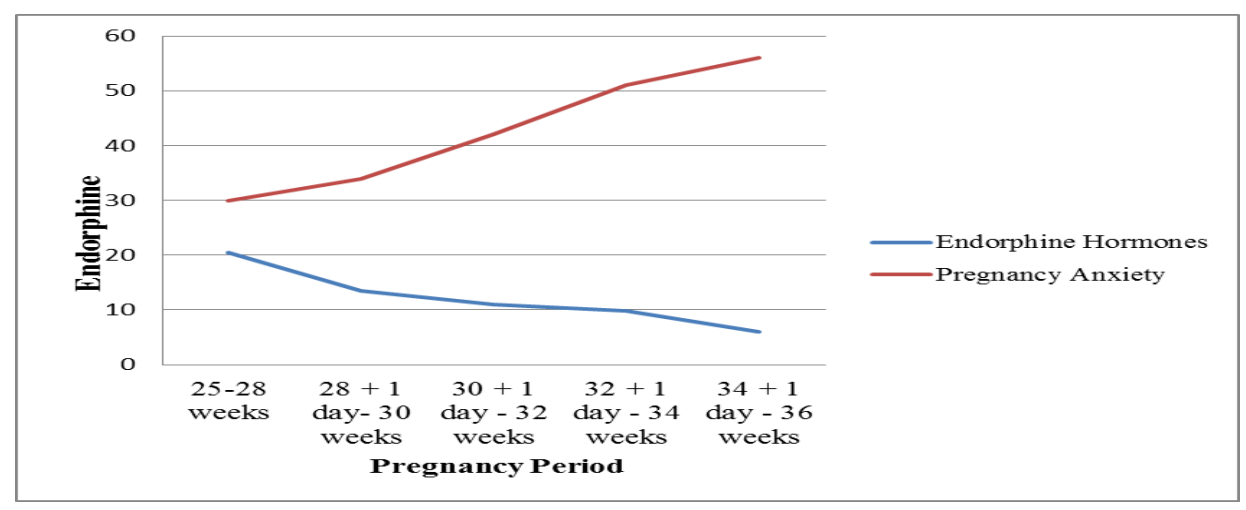

\section{Discussion}

Anxiety symptoms during pregnancy are higher compared to other periods of a woman's life, such as the gestation period and the postpartum period. Pregnancy causes physical, physiological, and psychological changes that occur very quickly. By nature, symptoms of anxiety are very manic or ever-changing in the antenatal period (17). Changes of anxiety level among pregnant women from time to time strongly influenced by positive optimism relating to coping strategies that are used to eliminate, reduce, and manage emotions.

On the contrary, the management of negative emotions such as ignoring, avoiding, or withdrawing, can worsen anxiety. Positive thoughts in the future can influence a person's perception and indirectly become control to reduce stress. Pregnant women who have optimistic was more able to control their emotions and overcome their problems than pregnant women who are pessimistic about their pregnancy (18).

Physiological changes in the body during pregnancy contribute to changes in the endocrine system through axis HPA dysregulation with the increase of CRH, ACTH, and cortisol. The placenta has an essential role in increasing $\mathrm{CRH}$ because at 25 weeks gestation since the placenta produces the Corticotropin-Releasing Hormone (pCRH) (4). CRH levels that remain high in pregnancy will inhibit the synthesis of endorphins that enter the 
peripheral circulatory system and contribute to mood disorders faced by pregnant and postpartum women (5-6).

The endorphin hormone has a vital role in dealing with psychological stress, pain management (16) and to maintain immunity during pregnancy (6). Endorphin synthesis is facilitated by a POMC protein precursor, which is an ACTH precursor in response to signals from the hypothalamus to release CRH in response to stress. Endorphins will stimulate the central nervous system and peripheral nervous systems such as the sympathetic nervous system and the parasympathetic nervous system (20). Dopamine can provide comfort, pleasure, and happiness (16). Endorphin synthesis can prevent the occurrence of diseases in the cardiovascular system, gastrointestinal system, urinary system, and genital system. Besides, it helps improve behavior and emotions as the body's natural coping strategy by increasing visceral organ function to maintain the balance of vital organs such as blood pressure, respiratory rate and heart cycle (21). Moreover, the endorphin hormone can be synthesized through immunological pathways, where T lymphocytes, B lymphocytes, monocytes, and magrofags have been shown to contain endorphins during inflammation (22).

The level of endorphin hormones decreases when pregnancy anxiety increases. Researchers would have a reason that endorphin can be used as a predictor of pregnancy anxiety; that is, endorphin synthesis changes very dynamically over time. Endorphins decrease during the 25 weeks up to 36 weeks of gestation, while pregnancy anxiety gets higher in the same period.

Because of the importance of the endorphins' role during pregnancy, it is recommended that pregnant women carry out activities that can increase the levels of endorphin hormones so that they can help to solve anxiety disorders during pregnancy. The events that can increase the secretion of endorphins in the bloodstream could be done through doing regular exercise for 30-60 minutes, doing meditation (23), Acupuncture and acupressure (24). These activities have been proven safe for pregnant women with healthy pregnancies.

\section{Conclusion}

It can be concluded that the endorphin hormone acts as one of the predictors of pregnancy anxiety or low levels of endorphins can increase pregnancy anxiety.

\section{References}

1. Lee AM, Lam S., Sze Mun Lau SM, Chong CS, Chui HW, Fong DY. Prevalence, course, and risk factors for antenatal anxiety and depression. Obs Gynecol. 2007;101(5):1102-12.

2. Keck M. Corticotropin-releasing factor, vasopressin, and receptor systems in depression and anxiety. Amino Acids. 2006;31:241-50.

3. Thomson M. The physiological roles of placental corticotropin-releasing a hormone in pregnancy and childbirth. J Physiol Biochem. 2013;69(3):559-73.

4. Hillhouse E, Grammatopoulos D. The molecular mechanisms underlying the regulation of the biological activity of corticotropin-releasing hormone receptors: implications for physiology and pathophysiology. Endocr Rev. 2006;27:260-286.

5. Smith R, Nicholson R. Corticotrophin releasing hormone and the timing of birth. Front Biosci. 2007;12:912-918. 
6. Yim IS, Glynn LM, Schetter CD, Hobel CJ, Chicz-Demet A, Sandman CA. Prenatal $\beta$ endorphin as an early predictor of postpartum depressive symptoms in euthymic women. J Affect Disord [Internet]. 2010;125(1-3):128-33.

7. Brummelte $S$, Galea LAM. Depression during pregnancy and postpartum: Contribution of stress and ovarian hormones. Prog Neuro-Psychopharmacology Biol Psychiatry [Internet]. 2010;34(5):766-76.

8. Bussel JCH, Spitz B, Demyttenaere K. Anxiety in pregnant and postpartum women. An exploratory study of the role of maternal orientations. J Affect Disord [Internet]. 2009;114(1-3):232-42. Available from: http://dx.doi.org/10.1016/j.jad.2008.07.018

9. Kinsella MT, Monk C. Impact of Maternal Stress, Depression \& Anxiety on Fetal Neurobehavioral Development. Clin Obstet Gynecol [Internet]. 2009;52(3):425-40.

10. Talge N, C N, Glover V. The Early Stress, Translational Research and Prevention Science Network: fetal and neonatal experience on child and adolescent mental health. Antenatal maternal stress and long-term effects on child neurodevelopment.

11. Qiao Y, Wang J, Li J, Wang J. Effects of depressive and anxiety symptoms during pregnancy o pregnant, obstetric, and neonatal outcomes: A follow-up study. 2012.

12. Petzoldt J, Wittchen H, Wittich JF, M E, Hofler, Martini J. Maternal anxiety disorders predict excessive infant crying: a prospective longitudinal study. Arch Dis Childhood. 2014;99(9):800-6.

13. Van den Heuvel M, Donkers F, Winkler I, Otte R, Den V, BR., et al. Maternal mindfulness and anxiety during pregnancy affect infants' neural responses to sounds. Soc Cogn Affect Neurosci. 2015;10(3):453-60.

14. Webb R, Ayers S. Cognitive biases in processing infant emotion by women with depression, anxiety, and post-traumatic stress disorder in pregnancy or after birth: A systematic review. Cogn Emot. 2014;1-17.

15. Teyhan A, Galobardes B, Henderson J. Child allergic symptoms and mental well-being: the role of maternal anxiety and depression. J Pediatr. 2014;165(3):592-9. e5.

16. Sharma DA, Verma D. Endorphins: Endogenous Opioid in Human Cells. World J Pharm Pharm Sci [Internet]. 2014;4(1):357-74.

17. Bayrampour H, Ali E, McNeil DA, Benzies K, MacQueen G, Tough S. Pregnancy-related anxiety: A concept analysis. Int J Nurs Stud [Internet]. 2016;55:115-30. Available from: http://dx.doi.org/10.1016/j.ijnurstu.2015.10.023

18. Nes L, Segerstrom S. Dispositional optimism and coping : a meta-analytic review. Inc 10,235-251. JSocPersonalSocPsychol. 2006;10:235-51.

19. Thomson M, Smith R. The action of hypothalamic and placental corticotropin-releasing factor on the corticotrope. Mol Cell Endocrinol. 1989;62:1-12.

20. Koneru A; Satyanarayana S; Rizman S. Endogenous Opioids : Their Physiological Role and Receptors. Glob J Pharmacol. 2009;3(3):149-53.

21. Veening JG, Barendregt HP. The effects of Beta-Endorphin: State change modification. Fluids Barriers CNS. 2015;12(1):1-22.

22. Rokade PB. Release of Endomorphin Hormone and Its Effects on Our Body and Moods : A Review. Int Conf Chem Biol Environ Sci [Internet]. 2011;431127(215):436-8.

23. Dhayal P. Effect of meditation on hormone creation and sporting performance. Int J Appl Res. 2015;1(4):123-6.

24. Cabığlu MT, Ergene N. Changes in Serum Leptin and Beta Endorphin Levels with Weight Loss by Electroacupuncture and Diet Restriction in Obesity Treatment. Am J 
Chin Med [Internet]. 2006;34(1):1-11. 